\title{
STRATEGI PENGEMBANGAN PERIKANAN TANGKAP DI KABUPATEN KEPULAUAN TALAUD
}

\author{
Strategy Development of Capture Fisheries in Talaud Island Regency
}

\author{
Oleh: \\ Jeti Pulu1, Mulyono S. Baskoro², Daniel R. Monintja², Budhi H. Iskandar², \\ Achmad Fauzi ${ }^{3}$ \\ ${ }^{1}$ BAPPEDA Kabupaten Talaud \\ ${ }^{2}$ Departemen Pemanfaatan Sumber Daya Perikanan, FPIK, IPB \\ 2 Departemen Ekonomi Sumber Daya Lingkungan, FEM, IPB \\ *Korespondensi: jeti_pulu@yahoo.com
}

Diterima: 12 Mei 2010; Disetujui: 25 Januari 2011

\begin{abstract}
This paper is discussing the continuation of previous research result in Talaud Island Regency that analyzed the loss due to illegal fishing activities in the area. Simulation result shows that if there is no illegal fishing, fisheries economic potential in Talaud is estimated to be in about IDR 7 billion or even might reach IDR 10 billion, but if this illegal fishing activities increased with acceleration, then in in the coming year-20th that potential will be negative. This means an economic loss of Talaud Regency. By means of a SWOT analysis, at least three main strategies are obtained those are as follows: increasing local budget alocation for marine and fisheries sectors, fisheries bussiness cooperation between Indonesia and Filiphina to eliminate illegal fishing practices and empowerment of the local community.
\end{abstract}

Key words: illegal fishing, strength, weakness, oportunity, threat, strategy and Talaud Island Regency

\begin{abstract}
ABSTRAK
Tulisan ini membahas kelanjutan hasil penelitian terdahulu di Kabupaten Kepulauan Talaud yang menganalisis kerugian akibat adanya praktek illegal fishing. Dari hasil simulasi didapatkan bahwa bila hal ini tidak terjadi, potensi ekonomi perikanan Kabupaten Kepulauan Talaud mencapai lebih dari Rp. 7 milyar rupiah bahkan bisa naik hingga Rp. 10 milyar. Sementara jika praktek illegal fishing berlangsung terus dengan rate yang meningkat potensi tersebut akan negatif pada tahun ke-20 yang tentu saja merugikan. Dari identifikasi dan analisis dengan mempertimbangkan faktor kekuatan, kelemahan, peluang dan ancaman diperoleh tiga prioritas utama dalam pembangunan perikanan dan kelautan di Kabupaten Kepulauan Talaud, yakni alokasi APBD untuk perikanan dan kelautan, kerjasama bisnis perikanan dengan Filipina untuk menekan praktek illegal fishing dan pemberdayaan masyarakat lokal.
\end{abstract}

Kata kunci: illegal fishing, kekuatan, kelemahan, peluang, ancaman, strategi dan Kabupaten Kepulauan Talaud

\section{PENDAHULUAN}

Tulisan ini merupakan kelanjutan dari tulisan pertama yang berjudul Pendekatan Bionomi Pada Peluang Pengembangan Perikanan
Tangkap Di Kabupaten Kepulauan Talaud (Pulu et al. 2010). Pada tulisan tersebut dibahas nilai kerugian akibat adanya praktek illegal fishing di Perairan Kabupaten Kepulauan Talaud. Potensi ekonomi perikanan Talaud jika tidak terja- 
di illegal fishing mencapai lebih dari Rp 7 milyar bahkan terus meningkat mencapai hampir $\mathrm{Rp}$ 10 milyar, namun jika terjadi illegal fishing oleh kapal-kapal perikanan dari Philipina, maka potensi ekonomi tersebut akan menurun hampir separuhnya. Sementara jika illegal fishing semakin marak dengan rate yang meningkat potensi ekonomi tersebut akan negative pada tahun ke 20 yang tentu saja sudah pada taraf yang merugikan potensi perikanan Kabupaten Kepulauan Talaud itu sendiri.

Dari hasil analisis bioekonomi dan model simulasi dapat didapatkan bahwa meski Kabupaten Kepulauan Talaud memiliki potensi sumber daya ikan yang dapat dimanfaatkan serta memiliki potensi untuk meningkatkan penerimaan daerah, kondisi wilayah perbatasan menyebabkan terjadinya kebocoran ekonomi dari sektor perikanan ke wilayah atau negara lain seperti Philipina. Kebocoran ekonomi merupakan potensi ekonomi yang hilang yang menjadi "korban" bagi masyarakat nelayan di wilayah Kabupaten Kepulauan Talaud.

Berdasarkan hal itu diperlukan beberapa terobosan kebijakan untuk mengurangi dampak kebocoran tersebut. Oleh karenanya, untuk mendapatkan strategi yang tepat maka perlu dikaji faktor-faktor yang akan memberikan pengaruh terhadap pengambilan suatu kebijakan seperti faktor kekuatan, kelemahan, ancaman dan peluang.

Sebagai lanjutan dari tulisan sebelumnya, maka bahasan ini ditujukan untuk mendapatkan arahan strategi yang sesuai untuk pengembangan perikanan tangkap di Kabupaten Kepulauan Talaud, agar kebocoran potensi ekonomi dari perikanan tangkap akibat perikanan tangkap illegal dapat ditekan.

\section{METODOLOGI PENELITIAN}

\section{Waktu dan Lokasi Penelitian}

Penelitian ini dilaksanakan selama 12 bulan, mulai bulan Januari sampai dengan Desember 2007. Lokasi penelitian di perairan Kabupaten Kepulauan Talaud.

\section{Pengumpulan Data}

Penentuan responden dalam penelitian ini ditetapkan berdasarkan teknik purposive sampling dengan pertimbangan bahwa responden adalah pelaku (individu atau lembaga) yang mempengaruhi pengambilan kebijakan, baik langsung maupun tidak langsung dalam pengelolaan dan pemanfaatan perikanan tangkap di perairan Kabupaten Kepulauan Talaud.
Responden terdiri dari para pejabat dan staf yang menguasai permasalahan yang berasal dari beberapa instansi/lembaga pemerintah seperti BAPPEDA Kabupaten Kepulauan Talaud, BAPEDALDA Kabupaten Kepulauan Talaud, Dinas Perikanan dan Kelautan Kabupaten Kepulauan Talaud, Perguruan Tinggi, Ketua $\mathrm{HNSI}$, pengusaha nelayan, lembaga permodalan, pakar ahli perikanan, ISPIKANI, Kantor Statistik Kabupaten Kepulauan Talaud, dan Lembaga Swadaya Masyarakat (LSM).

Tabel 1 berisikan lokasi pengambilan data dengan metode survei untuk menggali data dan informasi langsung dari lokasi penelitian. Data yang dikumpulkan adalah data primer dan data sekunder. Data Primer tentang komposisi jenis ikan dan jumlah alat tangkap yang digunakan. Data Sekunder berupa data statistik produksi perikanan baik provinsi maupun Kabupaten Kepulauan Talaud.

Selain survei deskripsi, survei untuk mendapatkan aspirasi responden juga dilakukan. Jumlah responden yang diwawancarai dalam aspek aspirasi terhadap pembangunan perikanan adalah 21 orang yang mewakili seluruh stakeholders perikanan dan kelautan (Tabel 2).

\section{Analisis data \\ Analisis Faktor-Faktor Strategis}

Analisis ini bertujuan untuk mendapatkan strategi yang akan dilaksanakan dalam pembangunan perikanan di Kabupaten Kepulauan Talaud.

\section{Analisis matriks IFE (Internal Factor Evalua- tion) dan EFE (External Factor Evaluation)}

Matriks IFE diperoleh dari hasil analisis lingkungan internal yaitu mencakup identifikasi faktor-faktor kunci internal berupa kekuatan dan kelemahan pembangunan perikanan di Kabupaten Kepulauan Talaud. Matriks EFE mengidentifikasi faktor-faktor kunci eksternal berupa peluang dan ancaman yang dihadapi dalam pembangunan perikanan di Kabupaten Kepulauan Talaud pada kondisi aktual saat ini. Selanjutnya, berdasarkan faktor kekuatan (strenght), kelemahan (weakness), peluang (opportunity) dan ancaman (threat) yang juga dikenal dengan metode SWOT (Rangkuti, 1999) strategi dirumuskan.

Penentuan prioritas strategi ditentukan dengan menggunakan metode AHP (Analysis Hierarchi Process) sebagaimana disampaikan oleh Saaty (1991). Selain itu, metode skoring (Haluan dan Nurani, 1998) juga digunakan dalam perhitungan matriks IFE dan EFE. 
Tabel 1 Jumlah tempat dan alat tangkap serta responden.

\begin{tabular}{|c|c|c|c|}
\hline \multirow{2}{*}{$\begin{array}{r}\text { TEMPAT } \\
\text { Kec. Salibabu }\end{array}$} & JENIS ALAT PENANGKAPAN & \multicolumn{2}{|c|}{ JUMLAH RESPONDEN } \\
\hline & $\begin{array}{l}\text { Pukat cincin, Pancing tonda, Jaring insang } \\
\text { hanyut }\end{array}$ & 7 & Orang \\
\hline Kec. Moronge & $\begin{array}{l}\text { Pukat cincin, Pancing tonda, Jaring insang } \\
\text { hanyut }\end{array}$ & 3 & Orang \\
\hline Kec. Lirung & $\begin{array}{l}\text { Pukat cincin, Pancing tonda, Jaring insang } \\
\text { hanyut }\end{array}$ & 3 & Orang \\
\hline Kec. Kolongan & Pancing ulur, Bubu & 3 & Orang \\
\hline Kec. Beo & Pancing ulur, Jaring insang hanyut & 4 & Orang \\
\hline Kec. Melonguane & $\begin{array}{l}\text { Pukat cincin, Pancing tonda, Jaring insang } \\
\text { hanyut }\end{array}$ & 4 & Orang \\
\hline Kec. Melonguane Timur & $\begin{array}{l}\text { Pukat cincin, bubu, pancing ulur, pancing } \\
\text { cumi }\end{array}$ & 5 & Orang \\
\hline Kec. Pulutan & $\begin{array}{l}\text { Pukat cincin, Pancing tonda, Jaring insang } \\
\text { hanyut }\end{array}$ & 3 & Orang \\
\hline Kec. Rainis & Pukat cincin, Pancing tonda, Jala tebar & 3 & Orang \\
\hline Kec. Nanusa & $\begin{array}{l}\text { Pukat cincin, pancing tegak, Penangkap } \\
\text { taripang }\end{array}$ & 6 & Orang \\
\hline Kec. Damau & Pukat cincin, pancing tonda, Garpu tombak & 3 & Orang \\
\hline Kec. Mangaran & Pukat cincin, Garpu tombak, muroami & 3 & Orang \\
\hline & TOTAL & 47 & Orang \\
\hline
\end{tabular}

Tabel 2 Jumlah Stakeholders yang di wawancarai.

\begin{tabular}{lc}
\multicolumn{1}{c}{ STAKEHOLDERS } & JUMLAH \\
\hline 1. Dinas Kelautan dan Perikanan & 2 \\
2. Dinas Tata Ruang dan Lingkungan Hidup & 1 \\
3. Badan Perencanaan Pembangunan Daerah & 1 \\
4. Kantor Perizinan Terpadu & 1 \\
5. Bagian Ekonomi Setda & 1 \\
6. Dinas Pariwisata & 1 \\
7. Badan Pusat Statistik & 1 \\
8. Badan Litbang & 1 \\
9. Bagian Pembangunan Setda & 1 \\
10. Dinas Pendidikan Nasional (Diknas) & 1 \\
11. Dinas Perhubungan & 1 \\
12. Dinas Pertanian & 1 \\
13. Dinas Kimpraswil & 1 \\
14. Dinas Perindustrian, Perdagangan dan Koperasi & 1 \\
15. Pengusaha & 2 \\
16. Himpunan Nelayan Seluruh Indonesia (HNSI) & 2 \\
17. Akademisi & 2 \\
\hline
\end{tabular}

\section{HASIL DAN PEMBAHASAN}

\section{Matriks IFE dan EFE}

Hasil analisis matriks IFE pada pembangunan perikanan di Kabupaten Kepulauan Ta- laud yang meliputi seluruh faktor kunci internal (kekuatan dan kelemahan) adalah nilai skor sebesar 2,593. Total nilai tersebut menunjukkan bahwa pembangunan perikanan di Kabupaten Kepulauan Talaud berada pada level rata-rata 
di dalam kekuatan internal seluruhnya. Hal ini mengisyaratkan bahwa dalam pembangunan perikanan di Kabupaten Kepulauan Talaud tersebut diperlukan adanya optimalisasi dalam memanfaatkan kekuatan yang dimiliki serta me- reduksi kelemahan yang ada dalam mencapai keberhasilan pembangunan perikanan di Kabupaten Kepulauan Talaud. Lebih rinci mengenai besarnya skor pada matriks IFE dapat dilihat pada Tabel 3.

Tabel 3 Matriks Internal Factor Evaluation (IFE).

\begin{tabular}{|c|c|c|c|}
\hline Faktor Internal & Bobot & Rating & Skor \\
\hline \multicolumn{4}{|l|}{ Kekuatan (Strengths): } \\
\hline 1. Potensi SDI yang belum mencapai titik MSY & 0,0908 & 4,000 & 0,363 \\
\hline 2. Kedekatan secara geografis dengan pasar & 0,0905 & 3,333 & 0,302 \\
\hline $\begin{array}{l}\text { 3. Komitmen PEMDA terhadap pengembangan kawasan } \\
\text { perbatasan }\end{array}$ & 0,0912 & 3,857 & 0,352 \\
\hline \multicolumn{4}{|l|}{ Kelemahan (Weaknessess): } \\
\hline 1. Unit penangkapan masih kurang & 0,0907 & 2,952 & 0,268 \\
\hline 2. Kemampuan SDM masih rendah & 0,0906 & 2,000 & 0,181 \\
\hline 3. Infrastruktur belum memadai & 0,0910 & 2,000 & 0,182 \\
\hline 4. Jumlah dan kemampuan kapal patroli belum memadai & 0,0912 & 1,857 & 0,169 \\
\hline $\begin{array}{l}\text { 5. Alokasi dana perikanan belum masuk skala prioritas } \\
\text { APBD }\end{array}$ & 0,0908 & 1,952 & 0,177 \\
\hline 6. Belum adanya industri pengolahan & 0,0911 & 2,429 & 0,221 \\
\hline 7. Sulitnya mendapatkan BBM & 0,0913 & 1,619 & 0,148 \\
\hline 8. Belum adanya rencana pengelolaan perikanan di daerah & 0,0909 & 2,524 & 0,229 \\
\hline Total & 1,0000 & & 2,592 \\
\hline
\end{tabular}

Sumber: Data Primer (diolah)

Tabel 4 Matriks EFE (External Factor Evaluation).

\begin{tabular}{|c|c|c|c|}
\hline Faktor Eksternal & Bobot & Rating & Skor \\
\hline \multicolumn{4}{|l|}{ Peluang (Opportunities) } \\
\hline $\begin{array}{l}\text { 1. Kerjasama bilateral antara Indonesia dengan negara } \\
\text { tetangga Filipina (BIMP-EAGA) }\end{array}$ & 0,1242 & 3,095 & 0,385 \\
\hline $\begin{array}{l}\text { 2. Kebijakan nasional untuk percepatan pembangunan } \\
\text { KTI }\end{array}$ & 0,1253 & 2,571 & 0,322 \\
\hline 3. Deklarasi Manado (WOC) & 0,1263 & 2,714 & 0,343 \\
\hline $\begin{array}{l}\text { 4. Perpres No. } 78 \text { Tahun } 2005 \text { tentang Pulau-Pulau Kecil } \\
\text { Perbatasan }\end{array}$ & 0,1252 & 2,190 & 0,274 \\
\hline \multicolumn{4}{|l|}{ Ancaman (Threats) } \\
\hline 1. Illegal market (transhipment) & 0,1258 & 1,190 & 0,150 \\
\hline 2. Illegal fishing & 0,1254 & 2,190 & 0,275 \\
\hline 3. Faktor cuaca & 0,1241 & 1,333 & 0,166 \\
\hline $\begin{array}{l}\text { 4. Tingkat kesenjangan kesejahteraan penduduk lokal } \\
\text { dengan negara tetangga sangat signifikan }\end{array}$ & 0,1235 & 2,381 & 0,294 \\
\hline Total & 1,0000 & & 2,208 \\
\hline
\end{tabular}

Sumber: Data Primer (diolah) 
Faktor kunci internal yang memiliki skor kekuatan tertinggi berdasarkan Tabel 1 adalah potensi sumber daya ikan yang belum mencapai titik MSY, yang ditunjukkan oleh nilai bobot sebesar 0,0908 dengan rating 4 dan skor sebesar 0,363; Komitmen PEMDA terhadap pengembangan kawasan perbatasan, yang ditunjukkan oleh nilai bobot sebesar 0,0912 dengan rating 3,857 dan skor sebesar 0,352 ; dan kedekatan secara geografis dengan pasar, yang ditunjukkan oleh nilai bobot sebesar 0,0905 dengan rating 3,333 dan skor sebesar 0,302; dimana potensi tersebut dapat dikembangkan untuk meningkatkan pembangunan perikanan di kawasan perbatasan. Faktor kunci ini merupakan peluang utama dalam pembangunan perikanan di Kabupaten Kepulauan Talaud.

Matriks IFE selain mengidentifikasi terhadap kekuatan internal pada pembangunan perikanan di Kabupaten Kepulauan Talaud, juga menunjukkan berbagai kelemahan dalam pembangunan perikanan di Kabupaten Kepulauan Talaud. Faktor internal yang memiliki skor kelemahan terbesar adalah sulitnya mendapatkan BBM, yang memiliki bobot 0,0913 dengan rating 1,619 sehingga skornya menjadi 0,148 ; dan jumlah serta kemampuan kapal patroli belum memadai, yang memiliki bobot 0,0912 dengan rating 1,857 , sehingga skornya menjadi 0,169 . Hal ini menunjukkan bahwa dalam pembangunan perikanan di Kabupaten Kepulauan Talaud kebijakan yang dikeluarkan sebaiknya berupaya mencukupi ketersediaan BBM dan jumlah kapal patroli, sehingga pembangunan perikanan di Kabupaten Kepulauan Talaud dapat memaksimalkan kekuatan yang dimiliki.

Dalam pembangunan perikanan di Kabu- paten Kepulauan Talaud dapat memanfaatkan peluang dan menghindari ancaman pengaruh lingkungan eksternal untuk menuju optimalisasi pembangunan perikanan di Kabupaten Kepulauan Talaud. Peluang dan ancaman yang dihadapi dalam pembangunan perikanan di Kabupaten Kepulauan Talaud disampaikan pada Tabel 4.

Tabel 4 menunjukkan bahwa faktor kunci eksternal yang memberikan peluang terbesar bagi pembangunan perikanan di Kabupaten Kepulauan Talaud adalah kerjasama bilateral antara Indonesia dengan Filipina (BIMP-EAGA). Hal ini ditunjukkan oleh nilai skor tertinggi yang dimiliki faktor kunci eksternal yaitu 0,1242 dengan bobot 0,385 dan rating 3,095. Peluang tersebut menunjukkan bahwa selama ini pembangunan perikanan di Kabupaten Kepulauan Talaud telah memberikan respon yang baik terhadap peluang pengembangan perikanan tangkap baik melalui kerja sama bilateral antara Indonesia-Filipina, kebijakan nasional percepatan pembangunana kawasan timur Indonesia, implementasi deklarasi Manado (WOC) ataupun implementasi Perpres 78/2005 tetang PulauPulau Kecil Perbatasan.

Faktor eksternal yang memberikan ancaman terbesar bagi pembangunan perikanan di Kabupaten Kepulauan Talaud adalah tingkat kesenjangan kesejahteraan penduduk lokal dengan negara tetangga, dalam hal ini Filipina, sangat signifikan. Hal ini ditunjukkan oleh nilai bobot 0,1235 dengan rating 2,381 dan skor 0,294 . Kondisi ini menunjukkan bahwa ancaman tingkat kesenjangan kesejahteraan penduduk lokal dengan Filipina akan memberikan dampak terhadap pembangunan perikanan di

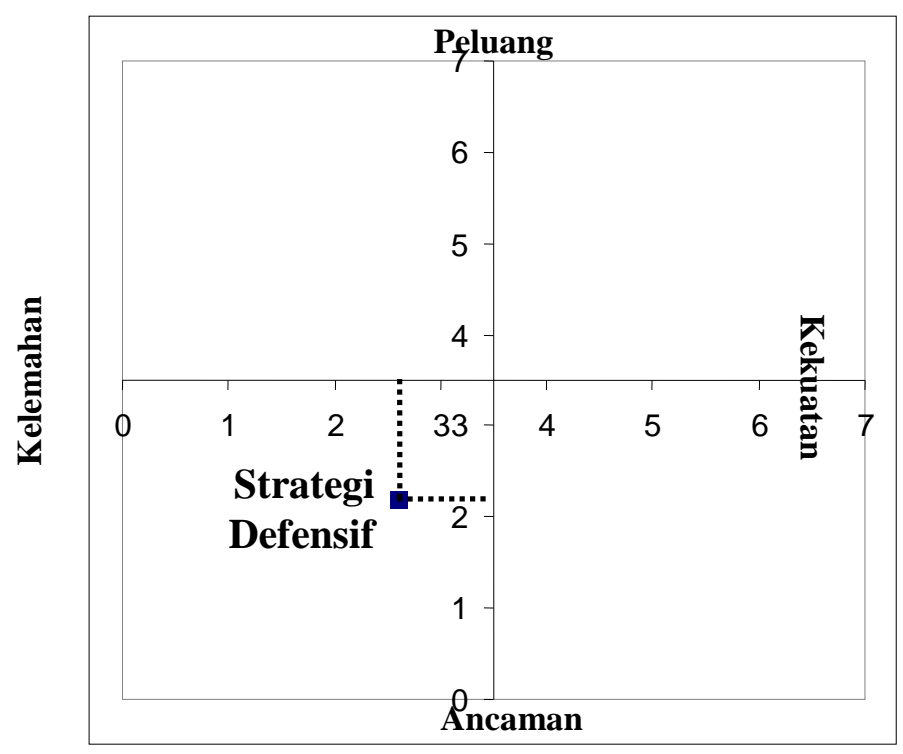

Gambar 1 Posisi kondisi pembangunan perikanan di Kabupaten Kepulauan Talaud. 
Tabel 5 Matriks SWOT strategi pembangunan perikanan Kabupaten Kepulauan Talaud.

\begin{tabular}{|c|c|c|}
\hline Faktor Eksternal & $\begin{array}{l}\text { Kekuatan (S) } \\
\text { 1. Potensi SDI yang belum } \\
\text { mencapai titik MSY } \\
\text { 2. Kedekatan secara geo- } \\
\text { grafis dengan pasar } \\
\text { 3. Komitmen PEMDA ter- } \\
\text { hadap pengembangan } \\
\text { kawasan perbatasan }\end{array}$ & $\begin{array}{l}\text { Kelemahan (W) } \\
\text { 1. Unit penangkapan masih ku- } \\
\text { rang } \\
\text { 2. Kemampuan SDM masih ren- } \\
\text { dah } \\
\text { 3. Infrastruktur belum memadai } \\
\text { 4. Jumlah dan kemampuan kapal } \\
\text { patroli belum memadai } \\
\text { 5. Alokasi dana perikanan belum } \\
\text { masuk skala prioritas APBD } \\
\text { 6. Belum adanya industri pengo- } \\
\text { lahan } \\
\text { 7. Sulitnya mendapatkan BBM } \\
\text { 8. Belum adanya rencana penge- } \\
\text { lolaan perikanan di daerah }\end{array}$ \\
\hline $\begin{array}{l}\text { Peluang (O) } \\
\text { 1. Kerjasama bilateral anta- } \\
\text { ra Indonesia dengan ne- } \\
\text { gara tetangga Filipina } \\
\text { (BIMP-EAGA) } \\
\text { 2. Kebijakan nasional untuk } \\
\text { percepatan pembangun- } \\
\text { an KTI } \\
\text { 3. Deklarasi Manado (WOC) } \\
\text { 4. Perpres No. 78 Tahun } \\
\text { 2005 tentang Pulau-pulau } \\
\text { kecil Perbatasan }\end{array}$ & $\begin{array}{l}\text { Strategi SO } \\
\text { 1. Kerjasama di bidang pe- } \\
\text { nangkapan ikan } \\
\text { 2. Kerjasama di bidang } \\
\text { pemasaran } \\
\text { 3. Menyusun blue print } \\
\text { pembangunan perikanan } \\
\text { di kawasan perbatasan } \\
\text { (mendukung RPJM \& } \\
\text { RPJP) }\end{array}$ & $\begin{array}{l}\text { Strategi WO } \\
\text { 1. Penambahan jumlah unit pe- } \\
\text { nangkapan } \\
\text { 2. Melakukan pendidikan dan pe- } \\
\text { latihan } \\
\text { 3. Pembangunan pelabuhan peri- } \\
\text { kanan } \\
\text { 4. Penambahan jumlah kapal pa- } \\
\text { troli } \\
\text { 5. Prioritasi alokasi anggaran } \\
\text { APBD untuk pembangunan } \\
\text { perikanan } \\
\text { 6. Pembangunan industri pengo- } \\
\text { lahan } \\
\text { 7. Pengadaan kapal khusus pe- } \\
\text { ngangkut BBM untuk kawasan } \\
\text { perbatasan } \\
\text { 8. Penyusunan Rencana Penge- } \\
\text { lolaan Perikanan (WPP 718) }\end{array}$ \\
\hline $\begin{array}{l}\text { Ancaman }(T) \\
\text { 1. llegal fishing } \\
\text { 2. llegal market (tranship- } \\
\text { ment) } \\
\text { 3. Faktor cuaca } \\
\text { 4. Tingkat kesenjangan kese- } \\
\text { jahteraan penduduk lokal } \\
\text { dengan negara tetangga } \\
\text { sangat signifikan }\end{array}$ & $\begin{array}{l}\text { Strategi ST } \\
\text { 1. Pengadaan kapal patroli } \\
\text { milik PEMDA } \\
\text { 2. Membangun sistem in- } \\
\text { formasi peramalan cua- } \\
\text { ca dalam kaitan dengan } \\
\text { musim penangkapan } \\
\text { 3. Pembangunan industri } \\
\text { perikanan untuk pening- } \\
\text { katan kesejahteraan ma- } \\
\text { syarakat lokal }\end{array}$ & $\begin{array}{l}\text { Strategi WT } \\
\text { 1. Penambahan unit penangkap- } \\
\text { an yang legal } \\
\text { 2. Pelatihan SDM dalam bidang } \\
\text { penangkapan ikan, pengolah- } \\
\text { an ikan, dan pemasaran } \\
\text { 3. Sosialisasi peraturan dan per- } \\
\text { undang-undangan yang ber- } \\
\text { kaitan dengan ilegal fishing } \\
\text { 4. Penambahan jumlah kapal pa- } \\
\text { troli }\end{array}$ \\
\hline
\end{tabular}

Kabupaten Kepulauan Talaud. Dampak yang dimaksud salah satunya adalah penjualan hasil tangkapan yang sebagian besar dilakukan di Filipina atau dengan nelayan Filipina dibandingkan dibawa ke pasar lokal. Hal ini tentunya me- nyebabkan Kabupaten Kepulauan Talaud kehilangan sebagian besar nilai jual dari hasil tangkapan tersebut. Selain itu faktor eksternal yang memberikan ancaman tertinggi kedua adalah terjadinya illegal fishing. Hal ini ditunjukkan oleh 
nilai bobot 0,1254 dengan rating 2,190 dan skor 0,275 . Illegal fishing akan memberikan dampak negatif terhadap pembangunan perikanan di Kabupaten Kepulauan Talaud, dimana sumberdaya ikan akan lebih banyak dimanfaatkan oleh nelayan Filipina dibandingkan nelayan lokal.

Hasil matriks EFE pembangunan perikanan di Kabupaten Kepulauan Talaud yang meliputi faktor peluang dan ancaman memiliki skor 2,208 (Gambar 1). Total nilai tersebut menunjukkan bahwa pembangunan perikanan di Kabupaten Kepulauan Talaud berada pada level rata-rata dalam upayanya untuk menjalankan strategi yang memanfaatkan peluang eksternal atau menghindari ancaman yang ada dalam mencapai optimalisasi pembangunan perikanan di Kabupaten Kepulauan Talaud.

\section{Perumusan Strategi}

Di dalam analisis ini dilakukan pemaduan antara elemen kekuatan, kelemahan, peluang, dan ancaman dengan menggunakan matriks SWOT. Tujuan dari pemaduan atau pencocokan ini adalah untuk menentukan alternatif strategi yang dipilih. Berdasarkan hasil analisis internal (kekuatan dan kelemahan) dan analisis eksternal (peluang dan ancaman) pembangunan perikanan di Kabupaten Kepulauan Talaud, maka strategi-strategi yang dapat dirumuskan sebagaimana tercantum pada Tabel 5 . Strategi ini disusun dengan menggunakan kekuatan yang dimiliki dan memanfaaatkan peluang yang ada. Berdasarkan uraian di atas maka dapat dibentuk matriks SWOT pembangunan perikanan Kabupaten Kepulauan Talaud seperti yang ditunjukkan pada Tabel 5.

\section{Prioritas Strategi dan Program Pemba- ngunan Perikanan di Kabupaten Kepu- lauan Talaud}

Strategi pembangunan perikanan di Kabupaten Kepulauan Talaud merupakan hal yang sangat penting. Hal ini disebabkan karena sektor perikanan merupakan salah satu sektor yang memiliki potensi yang dapat diandalkan sebagai sumber pemasukan daerah. Dari strategi yang dihasilkan melalui pemaduan faktor internal dan eksternal (Table 5), perlu disusun prioritas agar lebih jelas strategi apa yang perlu dijalankan terlebih dahulu. Penyusunan prioritas ini dilakukan dengan menggunakan analisis AHP. Hasil analisis AHP ini disampaikan pada Tabel 6 dan Gambar 2.

Hasil prioritas tersebut dapat dijelaskan sebagai berikut: APBD merupakan prioritas pertama karena komponen finansial merupakan unsur utama modal pembangunan semua sektor, termasuk sektor perikanan. Tanpa adanya alokasi APBD yang memadai tidak mungkin pembangunan perikanan di daerah terisolasi dan jauh dari daratan ini dapat dikembangkan. Alokasi APBD merupakan prasyarat utama untuk tercapainya pembangunan perikanan yang berkelanjutan dan menuju sektor unggulan. Jika

Tabel 6 Hasil prioritas alternatif strategi pembangunan perikanan di Kabupaten Kepulauan Talaud.

\begin{tabular}{clcc}
\hline No & \multicolumn{1}{c}{ Alternatif } & Bobot & $\begin{array}{c}\text { Urutan } \\
\text { Prioritas }\end{array}$ \\
\hline 1 & Prioritas APBD untuk kelautan dan perikanan & 0,157 & 1 \\
2 & Kerjasama di bidang bisnis perikanan dengan Filipina & 0,103 & 2 \\
3 & Pemberdayaan masyarakat local & 0,099 & 3 \\
4 & Pembentukan pasar & 0,084 & 4 \\
5 & Peningkatan jumlah unit penangkapan ikan & 0,077 & 5 \\
6 & Diklat & 0,072 & 6 \\
7 & Pembangunan industri pengolahan & 0,068 & 7 \\
8 & Peningkatan jumlah kapal pengawas & 0,061 & 8 \\
9 & Menyusun blueprint pembangunan perikanan & 0,058 & 9 \\
10 & Pembangunan prasarana pelabuhan & 0,051 & 10 \\
11 & Pengadaan kapal pengangkut ikan & 0,050 & 11 \\
12 & Sistem informasi perikanan dan cuaca & 0,045 & 12 \\
13 & Pengadan kapal BBM & 0,040 & 13 \\
14 & Penyusunan rencana pengelolaan WPP 717 & 0,036 & 14 \\
\hline
\end{tabular}




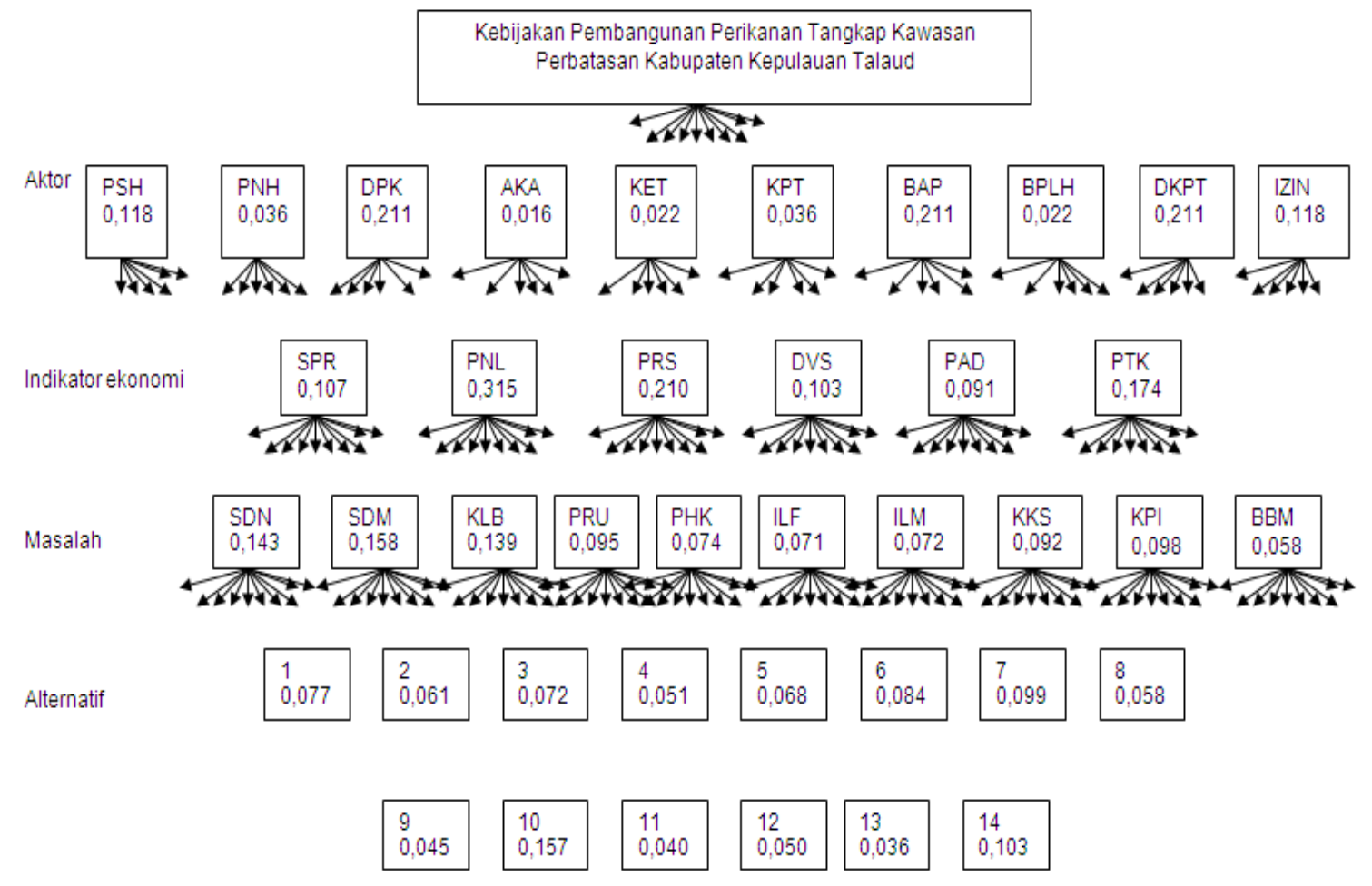

Gambar 2 Struktur hirarki dan hasil perhitungan AHP.

Tabel 5 Keterangan singkatan pada Gambar 2

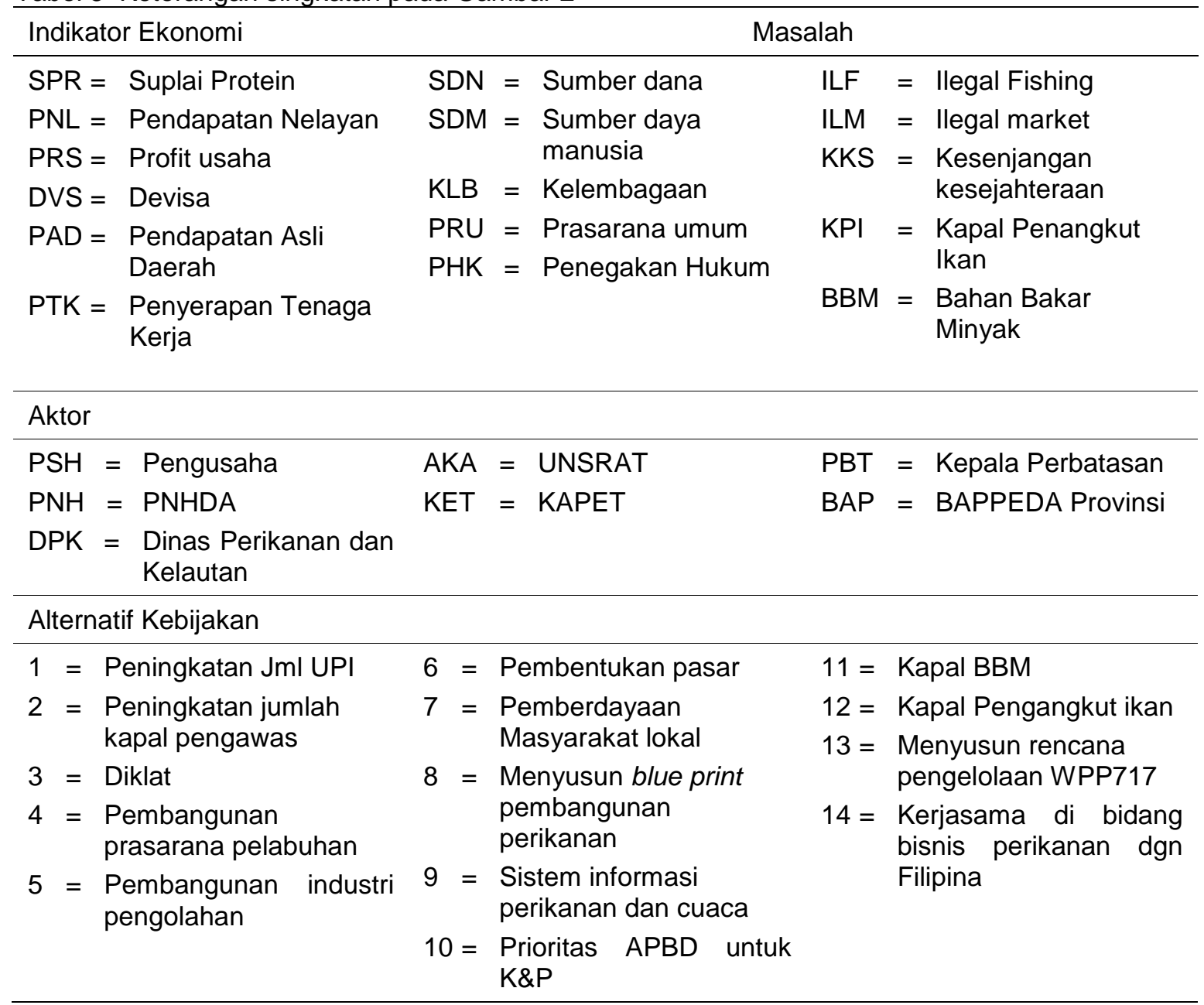


komponen ini tidak terpenuhi, maka sektor perikanan dan kelautan akan tetap terpinggirkan seperti yang terjadi sekarang dan akan lebih terpuruk lagi di masa mendatang. Dari pendapat para pakar perikanan saat wawancara dilakukan menyebutkan bahwa agar hal ini tidak terjadi maka alokasi APBD yang dimaksud tidak hanya diarahkan untuk pengadaan fisik seperti alat tangkap, kapal atau pembangunan pelabuhan, namun juga pendampingan dan pemberdayaan terhadap masyarakat lokal. Pemberdayaan ini diarahkan juga untuk mendapatkan nilai tambah dari produk perikanan, sehingga memiliki nilai jual yang lebih baik. Selain itu juga program diarahkan untuk kemudahan akses pasar.

Perhatian yang lebih memang diperlukan pada wilayah perbatasan khususnya bagi wilayah yang nilai perekonomiannya jauh berbeda seperti halnya wilayah Kabupaten Kepulauan Talaud dan Filipina. Secara pasti memang sulit menentukan prosentase alokasi APBD untuk pengembangan perikanan di Kabupaten Kepulauan Talaud, namun demikian diperkirakan bahwa alokasi antara $5 \%$ sampai $10 \%$ dari APBD untuk pengembangan perikanan akan mampu memberikan dampak pengganda yang cukup signifikan pada pembangunan perikanan di daerah tertinggal seperti Kabupaten Kepulauan Talaud.

Dilain pihak, dimasa mendatang bila sektor perikanan sudah berkembang dengan optimal maka subsektor ini akan berkontribusi baik terhadap PAD, sebagaimana diungkapkan oleh Kaleka et al. (2007) dimana pengoptimalan unit penangkapan ikan lokal di Kabupaten Nusa Tenggara Timur dapat meningkatkan PAD. Hal senada juga disampaikan oleh Yulistiyo et.al., 2006 yang mengkaji pengembangan armada perikanan tangkap di Ternate, Maluku Utara. Karunia et al. (2008) dari hasil penelitiannya di Kabupaten Kepulauan Seribu DKI Jakarta menyampaikan bahwa tanpa memasukkan sektor migas, pada periode 2001-2006 sektor pertanian memiliki peranan dominan bagi pertumbuhan nilai tambah Propinsi DKI Jakarta dengan subsektor utama adalah perikanan, yaitu sebesar $40,58 \%$.

Prioritas berikutnya adalah kerjasama dengan Filipina, sebagai daerah perbatasan yang langsung berhubungan dengan Filipina, pasar terdekat bagi produk-produk perikanan di daerah Kabupaten Kepulauan Talaud. Jika tidak ada perjanjian kerja sama maka penjualan produk perikanan ke Kabupaten Kepulauan Talaud dianggap illegal dan ini akan merupakan kebocoran ekonomi wilayah. Namun jika dilakukan kerjasama maka kedua belah pihak akan diuntungkan karena arus barang dan jasa yang mendukung sektor perikanan akan dengan mudah diterima di daerah Kabupaten Kepulauan Talaud dan sebaliknya. Salah satu bentuk kerja sama yang dapat dilakukan adalah melalui kerjasama pembebasan bea tarif masuk, dengan demikian harga barang-barang dari kedua belah tidak akan mengalami perbedaan harga yang jauh, yang akan memicu aliran asset dari satu daerah ke daerah yang lain. Bentuk kerja sama lainnya adalah melalui alih teknologi, dimana teknologi yang dikembangkan di daerah lain khususnya Filipina dapat di transfer ke Kabupaten Kepulauan Talaud dengan biaya yang lebih murah. Alih teknologi ini harus diimbangi pula dengan pengembangan sumber daya manusia melalui pengiriman tenaga-tenaga trampil di kedua belah pihak. Bentuk lain yang juga sangat relevan adalah menjadikan daerah perbatasan sebagai daerah otorita, dengan demikian diperlukan kerja sama menyangkut aspek politik seperti patroli bersama dalam mencegah terjadinya pencurian ikan dan pembebanan bersama pembiayaan pengawasan illegal fishing dengan Filipina melalui nota kesepahaman. Selanjutnya kesepakatan untuk melakukan relokasi pabrik pengolahan/pengalengan ikan yang ada di General Santos dipindahkan ke Kabupaten Kepulauan Talaud atau dengan membuka cabang pabrik pengolahan/pengalengan ikan di Kabupaten Kepulauan Talaud. Kerjasama di bidang industri pengolahan/pengalengan ikan ini akan menguntungkan kedua belah pihak karena selain bahan bakunya dekat berada di sekitar Kabupaten Kepulauan Talaud juga jarak yang ditempuh lebih dekat ke General Santos daripada ke Bitung. Pembagian hasil atau halhal lain akan diatur tersendiri dalam nota kesepahaman.

Komponen berikutnya yang juga sangat penting yakni menjadi prioritas ketiga adalah pemberdayaaan masyarakat. Komponen ini merupakan pembangkitan ekonomi secara mandiri dari wilayah Kabupaten Kepulauan Talaud sendiri. Dengan diberdayakannya masyarakat lokal maka mereka akan memiliki nilai tawar yang lebih baik dan memiliki kemampuan daya beli yang lebih baik sehingga produk perikanan juga diserap untuk konsumsi domestik. Selain itu pemberdayaan masyarakat memiliki keuntungan untuk menangkal gangguan-gangguan dari daerah perbatasan yang tidak menguntungkan Indonesia khususnya wilayah Kabupaten Kepulauan Talaud sendiri. Pemberdayaan masyararakat akan memberikan efek ganda berupa penciptaan kegiatan ekonomi lainnya dan membantu mengembangkan pasar produkproduk perikanan. Senada dengan yang disampaikan oleh Wisudo (2008) dari hasil penelitiannya di Nangroe Aceh Darussalam, bahwa masyarakat merupakan salah satu faktor pen- 
ting yang dapat menunjang keberhasilan suatu sistem pengembangan perikanan tangkap bertanggungjawab.

Prioritas berikutnya yang penting dalam pembangunan sektor perikanan dan kelautan di Kabupaten Kepulauan Talaud adalah pembentukan pasar khususnya pasar domestik. Pembangkitan pasar ini selain akan menyerap produk perikanan secara domestik, juga akan memperkuat ekonomi wilayah secara keseluruhan dan meningkatkan permintaan akan produk-produk perikanan. Pasar yang kuat juga akan menjadi faktor penarik bagi konsumen dari wilayah sekitar dan juga dari wilayah perbatasan dengan Filipina.

Komponen berikutnya yang menjadi pendukung dalam prioritas pembangunan perikanan di Talaud adalah peningkatan jumlah unit penangkapan ikan, lembaga pendidikan (diklat) dan pengolahan perikanan. Ketiganya akan membantu mendukung sektor perikanan dari sisi industri hillir, sehingga selain penguatan pada industri hulu, industri hilir juga perlu diperkuat sehingaa sisitim usaha perikanan di Kabupaten Kepulauan Talaud dapat terintgerasi dengan baik. Lembaga pendidikan dan latihan akan sangat membantu memenuhi kebutuhan sumber daya manusia yang berkualitas sehingga akan menunjang kelancaran industri perikanan di daerah ini. Tanpa dukungan tenaga kerja yang terampil, daya saing perikanan di Kabupaten Kepulauan Talaud akan kalah bersaing dengan wilayah perbatasan (Filipina) dan tidak akan memberikan nilai tambah yang lebih baik dari wilayah sekitarnya.

\section{KESIMPULAN DAN SARAN}

\section{Kesimpulan}

Dari hasil analisis SWOT dihasilkan 29 strategi pembangunan perikanan dan kelautan di Kabupaten Kepulauan Talaud dengan mempertimbangkan kekuatan, kelemahan, peluang dan ancaman. Dari ke-29 strategi tersebut 14 merupakan prioritas alternatif strategi dalam pembangunan perikanan dan kelautan di Kabupaten Kepulauan Talaud. Tiga prioritas utama adalah alokasi APBD untuk perikanan dan kelautan, kerjasama bisnis perikanan dengan Filipina untuk menekan praktek illegal fishing dan pemberdayaan masyarakat lokal.

\section{Saran}

Berdasarkan hasil kesimpulan didapatkan saran sebagai berikut:

1. Perlunya adanya patroli dari pihak terkait seperti TNI AL, Polairud, DKP, dan lainnya se- hingga mencegah terjadinya illegal fishing di daerah perbatasan.

2. Perlunya pembangunan fasilitas perikanan didaerah perbatasan sehingga hasil produksi yang ada dapat termanfaatkan dengan sebaik mungkin.

\section{DAFTAR PUSTAKA}

Widuso S.H. 2008. Analisis Pengembangan Perikanan Tangkap Bertanggungjawab di Provinsi Nangroe Aceh Darussalam. Bulletin PSP Vol. XVIII No. 1. April 2008. Departemen PSP FPIK IPB Bogor. Hal: $1-28$.

Karunia R.L., J. Haluan, D.R. Monintja \& Anny Ratnawati. 2008. Analisis Kebijakan Peningkatan Kesejahteraan Nelayan Kabupaten Adminitrasi Kepulauan Seribu. Bulletin PSP Vol. XVIII No. 1. April 2008. Departemen PSP FPIK IPB Bogor. Hal: 44-70.

Haluan J. \& Nurani T.W. 1998. Penerapan Metode Skoring dalam Penelitian Teknologi Penangkapan Ikan yang Sesuai untuk Dikembangkan di Suatu Wilayah Perairan. Bulletin Program Studi Pemanfaatan Sumberdaya Perikanan Vol. II, No. 1. Fakultas Perikanan, Institut Pertanian Bogor: Hal 3-16.

Kaleka D.M.W., B.H. Iskandar, D.R. Monintja \& M.S. Baskoro. 2007. Analisis Pengembangan Armada Perikanan Tangkap Di Kabupaten Kupang Nusa Tenggara Timur. Bulletin PSP Vol. XVI No. 2, Agustus 2007. ISSN 0251-286X. Departemen Pemanfaatan Sumber daya Perikanan, Fakultas Perikanan dan IImu Kelautan, Institut Pertanian Bogor.

Pulu J., M.S. Baskoro, D.R. Monintja \& B.H. Iskandar, 2010. Pendekatan Bionomi Pada Peluang Pengembangan Perikanan Tangkap Di Kabupaten Kepulauan Talaud. Bulletin PSP Vol. XIX No. 3, November 2010. ISSN 0251-286X. Departemen Pemanfaatan Sumber daya Perikanan, Fakultas Perikanan dan IImu Kelautan, Institut Pertanian Bogor.

Rangkuti F. 1999. Analisis SWOT: Teknik Membedah Kasus Bisnis. Gramedia Pustaka Utama. Jakarta, hal 135

Saaty L. 1991, Pengambilan Keputusan Bagi Para pemimpin, PT Pustaka Binaan Pressindo, Jakarta hal 45

Yulistyo, M.S. Baskoro, D.R. Monintja \& B.H. Iskandar. 2006. Analisis Kebijakan Peng- 
embangan Armada Penangkapan Ikan Berbasis Ketentuan Perikanan yang Bertanggung Jawab di Ternate, Maluku Utara. Buletin PSP Volume XV. No 1. hal 70. 